\title{
Clinical profile of end stage renal disease in patients on maintenance haemodialysis in a tertiary hospital
}

\author{
Durga Dhungana $^{1^{*}}$ (D) Chandra Bahadur Pun ${ }^{1}$, Bidhya Banstola ${ }^{2}$ iD
}

'Department of Medicine, Gandaki Medical College Teaching Hospital and Research Center, Pokhara, Nepal ${ }^{2}$ Lecturer, Nursing Program, Manipal College of Medical Sciences, Pokhara, Nepal

\begin{abstract}
Introduction and Objectives: Chronic kidney disease is an increasing health problem worldwide and the burden of such patients is increasing in developing countries like Nepal as well. The final treatment for End Stage Renal Disease is only renal replacement therapy. The objective was to study the demographic and clinical profile of patients with End Stage Renal Disease undergoing haemodialysis. Methods: This was a prospective, observational study carried out in a tertiary hospital after obtaining ethical consent from the Institutional Review Board. The study period was from June 1st to August 31st, 2019. Thirty seven patients, older than 15 years who were on maintenance haemodialysis on regular basis in the hospital for at least 3 months were selected for the study. Patient's records were used for the data collection as well as direct questionnaire to the patients on follow up for routine haemodialysis. Data were entered into Statistical Package for the Social Sciences 21 and descriptive analysis was done. Results: Twenty-six patients were under 50 years with male: female ratio of 1.64:1. Mean duration of haemodialysis of patients was 3.82 years. Most common cause for end stage renal disease was hypertension followed by idiopathic cause. Anaemia and hypocalcaemia were found to be the common complications associated with the patients. Conclusions: Prevention and early treatment may be the key to decrease the incidence of chronic kidney disease patients and also halt the progression to End stage renal disease.
\end{abstract}

Keywords: anaemia, chronic kidney disease, diabetes mellitus, haemodialysis, hypertension

\section{Correspondence to:}

Dr Durga Dhungana, MBBS, MD

Lecturer, Department of Medicine, Gandaki Medical College Teaching Hospital and Research Center,

Pokhara, Nepal

Email: durga2008@gmail.com

Submitted: September 20, 2020

Accepted: November 25, 2020

To cite: Dhungana D, Pun CB, Banstola B. Clinical profile of end stage renal disease in patients on maintenance haemodialysis in a tertiary hospital. JGMC Nepal. 2020;13(2):169-72.

DOI: $10.3126 /$ jgmcn.v13i2.31336

\section{INTRODUCTION}

End-stage renal disease represents a stage of Chronic Kidney Disease (CKD)where the accumulation of toxins, fluid, and electrolytes normally excreted by the kidneys leads to death unless the toxins are removed by renal replacement therapy, using dialysis or kidney transplantation. ${ }^{1}$ The incidence of End Stage Renal Disease (ESRD) patients in USA is projected to increase by $29 \%$ to $68 \%$ to between 971,000 and $1,259,000$ in $2030 .^{2}$

There is wide geographic variation in the cause of kidney disease. In developed countries, hypertension and diabetes are the most frequent causes of CKD, especially in the elderly. Specialized diagnostic testing, such as kidney biopsy or invasive imaging studies are performed only when it is essential to confirm some diagnoses and the benefits justify the risks and cost. It is anticipated that cause of disease will not be known with certainty for many patients with CKD but can be either inferred or not known. ${ }^{3}$

Studies have been carried out in $\mathrm{Nepal}^{4}{ }^{4}$ however limited in number in this part of Nepal. Hence this study was carried out 
to assess the demographic and clinical profile of patients undergoing haemodialysis. The objective of this study was to assess the demographic and clinical profile of patients with ESRD undergoing haemodialysis.

\section{MATERIALS AND METHODS}

This was a prospective observational study conducted in the haemodialysis unit of medicine department of Gandaki Medical College Teaching Hospital and Research Center over a period of three months from June $1^{\text {st }}$ to August $31^{\text {st }}$, 2019. Convenient sampling method was used and included all ESRD patients undergoing haemodialysis in the hospital unit for at least three months periods. Data collection was started after taking ethical approval from the institutional review committee. Data were collected after taking written informed consent from the patients as per the proforma. The Proforma included socio-demographic characteristics, details of haemodialysis and laboratory parameters. The data were analysed using Statistical Package for Social Sciences (SPSS) software and descriptive analysis was done and expressed as percentages, ratios and mean values.

\section{RESULTS}

Most (26) of the patients were under 50 years with range from 22 to 67 years. Male: female ratio of 1.64:1. Mean duration of haemodialysis of patients was $3.82 \pm 1.84$ years. (Table 1)

Table 1: Age and sex distribution of ESRD $\quad \mathrm{N}=37$

\begin{tabular}{cccc}
\hline Age group & Male n (\%) & Female n (\%) & n (\%) \\
$21-30$ & $2(5.4)$ & $1(2.7)$ & $3(8.1)$ \\
$31-40$ & $9(24.3)$ & $5(13.5)$ & $14(37.8)$ \\
$41-50$ & $2(5.4)$ & $7(18.9)$ & $9(24.3)$ \\
$51-60$ & $6(16.2)$ & $1(2.7)$ & $7(18.9)$ \\
$61-70$ & $4(10.8)$ & 0 & $4(10.8)$ \\
Total & $23(62.2)$ & $14(37.8)$ & \\
Mean Age: $44.95($ S.D $=10.93)$ & & \\
\hline
\end{tabular}

Table 2. Causes of CKD $\mathrm{N}=37$

\begin{tabular}{cc|}
\hline Cause of CKD & Number \\
Hypertension & 19 \\
Diabetes Mellitus & 3 \\
Chronic Glomerulonephritis & 2 \\
Obstructive & 2 \\
Unknown & 11 \\
\hline
\end{tabular}

Most common cause for end stage renal disease was hypertension (19) followed by diabetes mellitus. However approximately one-third (11) of the patients hadn't an established cause which may be due to late presentation to the tertiary hospital or due to delay in seeking treatment at an early CKD stage. (Table 2)
The mean haemoglobin level was 8.5 gm\%. Large variation in the levels of haemoglobin, phosphate and potassium were also observed. (Table 3)

Table 3: Lab parameters $\mathrm{N}=37$

\begin{tabular}{ccccc}
\hline $\begin{array}{c}\text { Lab Values } \\
\text { Haemoglobin }(\mathrm{gm}\end{array}$ & Mean & S.D & Minimum & Maximum \\
$\begin{array}{c}\text { \%) } \\
\text { Sodium(mmol/L) }\end{array}$ & 138 & 3 & 131 & 146 \\
$\begin{array}{c}\text { Potassium } \\
\text { (mmol/L) }\end{array}$ & 5.1 & 0.89 & 3.3 & 7.5 \\
$\begin{array}{c}\text { Phosphate (mg/dL) } \\
\begin{array}{c}\text { Uric acid (mmol/L) } \\
\text { Calcium (mmol/L) }\end{array}\end{array}$ & 0.29 & 0.07 & 0.12 & 0.52 \\
\hline
\end{tabular}

Anaemia and hypocalcaemia were found to be the common complications associated with the patients. (Table 4)

Table 4: Complications/Electrolyte disturbances in ESRD cases $\mathrm{N}=37$

\begin{tabular}{cc}
\hline Complications & Number \\
Anaemia & 37 \\
Hypocalcaemia & 23 \\
Hyperkalaemia & 10 \\
Hyponatremia & 5 \\
Hyperuricemia & 2 \\
Hyperphosphatemia & 3 \\
\hline
\end{tabular}

\section{DISCUSSION}

Out of 37 patients in the study, 23 patients were male which were similar to the study done in Nepal Medical College in 2008 A.D. ${ }^{5}$ This is also similar to the study done in India by Sandip et al. in 2017 A.D. ${ }^{6}$ A study done in Iran in 2009 A.D also had male majority in presentation. ${ }^{7}$ This shows that male are frequently seeking treatment facilities for their problems and females may be neglected for the treatment purpose.

The variation in age presentation of ESRD patients to the hospital is an alarming sign. Presentation of ESRD at age low as 22 years is a challenging issue to the health system of Nepal. Three-fourths of the patients on haemodialysis were under 50 years of age is a key message that the productive age-group are affected by CKD and needs early attention and prevention measures to prevent progression to CKD and eventually to ESRD and replacement therapy. This finding is similar to other studies done in India, Iran, Cameroon and 
Nepal.5-8 A systemic review analysing the epidemiology of CKD in sub-Saharan Africa revealed mean age of 37 years. ${ }^{9}$ This is different to the studies done in different states of United States of America (USA) where the mean age of presentation was above 62 years. ${ }^{10-12}$ The variation in age of presentation is likely a reflection of health status, health availability and accessibility in different regions of the world.

Mean duration of haemodialysis suggests that patients were on regular haemodialysis; however, comparison or longer duration of study would provide us with more findings related to follow-up and complications too. This was similar to the study done in Iran. ${ }^{7}$

This study showed hypertension as a leading casus of ESRD which is similar to the study done in Kathmandu. ${ }^{5}$ The study done in Cameroon also showed similar finding. ${ }^{8}$ Due to the availability of haemodialysis as free treatment under the Government of Nepal throughout the country, more and more patients who previously couldn't afford haemodialysis are getting this service. As of late presentation most are hypertensive at time of presentation with hypertensive organ damages. Second to hypertension, most had unknown cause. This is similar to the study done in Kathmandu where idiopathic was the third most common cause of ESRD. ${ }^{5}$ Late presentation to a tertiary care center, the unavailability of nephrologists throughout the country and unavailability of standard lab for processing the sample could have overestimated idiopathic as a cause for ESRD. This finding is also similar to the study done in India. ${ }^{6}$ Diabetes mellitus was the third most common cause reported. These findings show that prevention, early diagnosis and regular treatment of hypertension and diabetes mellitus can halt the progression to CKD and eventually to ESRD. Hence government of Nepal should give more focus on prevention and basic treatment availability and accessibility to the Nepalese people.

Anaemia is one of the complications frequently encountered in ESRD patients. Anaemia is caused by multifactorial factors and its correction can help to cause decrease in morbidity and mortality. This study showed that all patients had anaemia. This is similar to the study in Kathmandu in which $85 \%$ were anaemic. ${ }^{5}$ The cause is that anaemia of CKD is multifactorial and its correction needs use of different therapies. ${ }^{13}$ However due to cost issues, patients can't afford such therapy regularly. Most patients rely more on blood transfusion for anaemia correction.

Electrolyte disturbances were not seen in majority of the patients. This is inconsistent with the findings in other studies. $^{6}$ This is likely due to regular haemodialysis as advised, regular follow-up and doing as per the advice by the doctors. Hyperkalaemia was seen in more cases as compared to hyponatremia possibly due to dependence on blood transfusion for correction of anaemia. Other possible reasons could be not strictly adhering to the dietary advices.

Mineral and bone disorders are also common complications seen in ESRD patients. ${ }^{14}$ Hypocalcaemia was also a common finding in the patients. Dietary pattern and medical therapy are measures to correct hypocalcaemia. Financial constraints may have a role in this. It would have been better if there was availability of other biochemical parameters like Parathyroid hormone.

The limitations of this study are that the sample size was small. Multicentre study could have added more value to its findings.

\section{CONCLUSIONS}

Timely diagnosis of known risk factors of CKD mainly hypertension and diabetes mellitus and their early and prompt treatment can halt the progress of patients to ESRD stage. Besides, timely referral of patients with unexplained cause for CKD can provide the patient with better options for treatment.

Disclaimer: The abstract of this article has been presented as a POSTER presentation via online medium in World Congress of Nephrology 2020. DOI: https://doi.org/10.1016/j. ekir.2020.02.748

\section{REFERENCES}

1. Kasper D, Fauci A, Hauser S, Longo D, Jameson J, Loscalzo J. Harrison's principles of internal medicine, $19 \mathrm{e} 2015$.

2. McCullough KP, Morgenstern H, Saran R, Herman $\mathrm{WH}$, Robinson BM. Projecting ESRD incidence and prevalence in the United States through 2030. Journal of the American Society of Nephrology. 2019;30(1):12735. DOI: https://doi.org/10.1681/ASN.2018050531.

3. Decreased G. Definition and classification of CKD. Kidney International. 2013;3:19-62. DOI: https://doi. org/10.1038/kisup.2012.64

4. Hada R, Khakurel S, Agrawal R, Kafle R, Bajracharya S, Raut K. Incidence of end stage renal disease on renal replacement therapy in Nepal. Kathmandu University Medical Journal. 2009;7(3):301-5. DOI: https://doi. org/10.3126/kumj.v7i3.2742

5. Chhetri P, Manandhar D, Bhattarai S, Pahari L, Shrestha R. Chronic kidney disease 5 on hemodialysis in Nepal Medical College Teaching Hospital. Nepal Medical College journal: NMCJ. 2008;10(1):8. 
6. Chaudhari ST, Sadavarte AV, Chafekar D. Clinical profile of end stage renal disease in patients undergoing hemodialysis. MVP Journal of Medical Science. 2017;4(1):8-13. DOI: https://doi.org/10.18311/ mvpjms/0/v0/i0/8555

7. Noshad H, Sadreddini S, Nezami N, Salekzamani Y, Ardalan M. Comparison of outcome and quality of life: haemodialysis versus peritoneal dialysis patients. Singapore medical journal. 2009;50(2):185.

8. Halle MP, Takongue C, Kengne AP, Kaze FF, Ngu KB. Epidemiological profile of patients with end stage renal disease in a referral hospital in Cameroon. BMC nephrology. 2015;16(1):59. DOI: https://doi. org/10.1186/s12882-015-0044-2

9. Stanifer JW, Jing B, Tolan S, Helmke N, Mukerjee $\mathrm{R}$, Naicker $\mathrm{S}$, et al. The epidemiology of chronic kidney disease in sub-Saharan Africa: a systematic review and meta-analysis. The Lancet Global Health. 2014;2(3):e174-e81. DOI: https://doi.org/10.1016/ S2214-109X(14)70002-6

10. Bloembergen WE, Port FK, Mauger EA, Wolfe RA. A comparison of mortality between patients treated with hemodialysis and peritoneal dialysis. Journal of the American Society of Nephrology. 1995;6(2):177-83. DOI: https://doi.org/10.1681/ASN.2018050531
11. Ganesh SK, Hulbert-Shearon T, Port FK, Eagle K, Stack AG. Mortality differences by dialysis modality among incident ESRD patients with and without coronary artery disease. Journal of the American Society of Nephrology. 2003;14(2):415-24. DOI: https://doi.org/10.1097/01. ASN.0000043140.23422.4F

12. Muntner P, Judd SE, Gao L, Gutiérrez OM, Rizk DV, McClellan W, et al. Cardiovascular risk factors in CKD associate with both ESRD and mortality. Journal of the American Society of Nephrology. 2013;24(7):1159-65. DOI: https://doi.org/10.1681/ASN.2012070642

13. McMurray JJ, Parfrey PS, Adamson JW, Aljama P, Berns JS, Bohlius J, et al. Kidney disease: Improving global outcomes (KDIGO) anemia work group. KDIGO clinical practice guideline for anemia in chronic kidney disease. Kidney International Supplements. 2012;2(4):279-335. DOI: https://doi.org/10.1038/kisup.2012.37

14. Wang AY-M, Akizawa T, Bavanandan S, Hamano T, Liew A, Lu K-C, et al. 2017 Kidney Disease: Improving Global Outcomes (KDIGO) Chronic Kidney Disease-Mineral and Bone Disorder (CKD-MBD) Guideline Update Implementation: Asia Summit Conference Report. Kidney international reports. 2019;4(11):1523-37. DOI: https://doi.org/10.1016/j.ekir.2019.09.007 